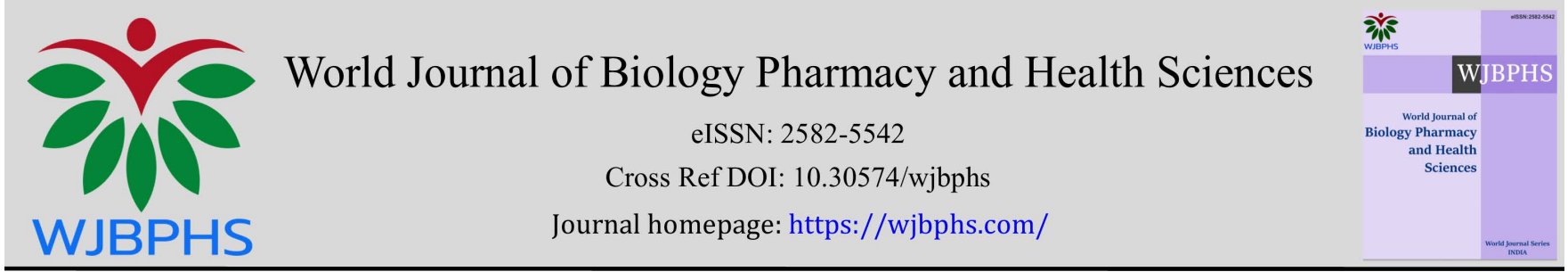

(RESEARCH ARTiCLE)

\title{
Body composition of Tashkent school-aged boys
}

Sevara Tulkinovna Fayzullaeva, Yulduz Ravshan qizi Kuvandikova, Diyora Azimovna Shukurova, Nilafar Nodirjon qizi Khaydarova and Lubov Salijanovna Kuchkarova *

Department of Human and Animal Physiology of National University of Uzbekistan, Tashkent, Uzbekistan.

World Journal of Biology Pharmacy and Health Sciences, 2021, 07(01), 059-062

Publication history: Received on 12 May 2021; revised on 26 June 2021; accepted on 28 June 2021

Article DOI: https://doi.org/10.30574/wjbphs.2021.7.1.0064

\begin{abstract}
Background: Body composition in periods of childhood, puberty and adolescent is a marker of metabolic changes that occur during these periods of growth and maturation, and, thus, it is an important information regarding child and adolescent health.
\end{abstract}

Purpose: The purpose is to study the age-related body index mass and body composition in the different age school boys in Tashkent city.

Method: Boys body composition was measured by analyzer "Tanita BC 543" (Japan) in the morning between 9.00-10.00 p.m. Body composition parameters were determined in boys of three stage of development: childhood (seven year old), early adolescence (twelve year old), and late adolescence age (eighteen year old).

Results: The obtained data show that as boys grow and develop, mass of all body components increased. The greatest increase was in adipose tissue, and the least one was in content of bone minerals. It was found 7-year-old children were underweight, but by the age of 18 there weight approached the normal value. However, weight normalization occurs due to an increase in adipose tissue. It is indirectly indicated a growing risk in the boys predisposition to the diabetes.

Keywords: Child; Adolescent; Body composition; Body mass index

\section{Introduction}

Currently, to assess public health the bioimpedance analysis and determination of body mass index are widely used. Bioimpedance analysis is based on measuring the electrical conductivity of biological tissues, such as adipose, muscle, body bone minerals etc. [1]. Taking in account the non-invasiveness, ease of use and low material costs of this method, the use of bio-impedance metry is convenient for mass screenings and the subsequent justification of medical and preventive programs for the correction of nutrition and lifestyle of organized groups [2;3].

Body composition in adults, when the ratio of body components is more or less stable, has been extensively well investigated [2, 3, 4]. In children and adolescents the body composition except genetic and climatic-geographic conditions depends on the high rates of growth and development [5]. Therefore, the common standards for body composition in children and adolescents has not been well studied. Thus there is a need for additional research in this direction. Detection of negative shifts in weight and body composition will help starting prevention work on their correction and prevention of undesirable health consequences timely [6].

\footnotetext{
${ }^{*}$ Corresponding author: Kuchkarova Lubov Salijanovna

Departmet of Human and Animal Physiology of National University of Uzbekistan, Tashkent Uzbekistan.
} 
The purpose of the research is to study the age-related body index mass and body composition in the different age school boys in Tashkent city.

\section{Material and methods}

\subsection{Tested school boys}

Boys of different age from the 243rd secondary school in Tashkent took part in the study. Body composition parametrs were studied in 3 periods of development: childhood, early adolescence and late adolescence. In the first group, children were seven ( $7.1 \pm 0.4$ ), years old, in the second and third groups boys were twelve (12.1 \pm 0.7$)$ and eighteen (17,8 \pm 0.5$)$ years old respectively. Only indigenous Uzbeks were tested. Voluntary informed consent was obtained from all participating children and their parents.

\subsection{Anthropometry measurement}

Height and body weight were identified with minimal clothing and bare feet. Body height was measured to the nearest $0.5 \mathrm{~cm}$ using a mechanical stadiometer RM 2 Diakoms (Russia). Body mass were measured using analyzer Tanita BC543 (Japan). The body mass index was calculated by the formula BMI $=\mathrm{m} / \mathrm{h}^{2}$ where $\mathrm{m}$ was a school boy's weight in kilograms and $\mathrm{h}^{2}$ was their height in meters squared.

\subsection{Body composition analysis}

Analysis of body composition was carried out in the morning between 10.00-11.00 using the analyzer "Tanita BC-543 " according to the standard scheme. A comparative assessment of the values of body height, body weight, body mass index, fat mass, lean mass, muscle mass, bone mineral mass and total water content was carried out.

\subsection{Statistics}

Comparison of indicators was performed depending on age, as well as calculation of mean group values (M) and standard error of the means (SE). Differences were considered significant at $p \leq 0.05$. Data processing was carried out using the standard package of statistical functions Microsoft Excel, 2010.

\section{Results}

\subsection{Anthropometric measurement}

Table 1 shows body height, body weight and body mass index in school boys of different ages. It turned out that 7 year old boys had a body mass index below the normal value of WHO standards. (13.1-17.0). However, as children grew and developed, their body mass index increased. So, in 12-year-old adolescents, the body mass index manifested itself at the lower limit of the norms, and in 18-year-old adolescents, the body mass index approached the values of the WHO norms (16.9-24.3).

Table 1 Height, body weight and body mass index in schoolboys of different age (M $\pm S E ; n=36-38)$

\begin{tabular}{|c|c|c|c|}
\hline \multirow[b]{2}{*}{ Parameters } & \multicolumn{3}{|c|}{ Age (years) } \\
\hline & 7 & 12 & 18 \\
\hline Height $(\mathrm{cm})$ & $114.7 \pm 9.8$ & $156.4 \pm 8.4$ & $174.2 \pm 6.2$ \\
\hline Weight(kg) & $15.3 \pm 0.8$ & $32.9 \pm 2.7$ & $58.2 \pm 4.8$ \\
\hline $\mathrm{P}$ & - & $<0.001$ & $<0.001$ \\
\hline BMI & $11.5 \pm 0.8$ & $13.5 \pm 1.4$ & $19.2 \pm 1.2$ \\
\hline $\mathrm{P}$ & - & $>0.1$ & $<0.001$ \\
\hline
\end{tabular}

$\mathrm{P}$ - Statistical significance of differences in comparison with the previous age 


\subsection{Body composition}

Table 2 shows the body composition components of boys in different stage of growth and development. In 12-year-old teenagers, compared with 7-year-old boys, the absolute content of fat, lean mass, muscle mass, mass of minerals of bone tissue and total water increased by $2.1 ; 1.7 ; 1.8 ; 1.2$ and 1.6 respectively. The increase of boy's body weight in late adolescence compared with early adolescence was accompanied by an increase in the weight of all body components. In 18-year-old boys fat mass increased by 2.3 times, lean mass by 1.8 times, muscle mass by 1.2 times and bone mineral mass by 1.2 times compared to 12-year-olds. The mineral content in 12-year-olds increased sharply in comparison with 7-year-olds, but then it was remained at the same level during adolescence.

Table 2 Body composition components in schoolboys of different age (M \pm SE; n=36-38)

\begin{tabular}{|l|l|c|c|}
\hline \multirow{2}{*}{\multicolumn{1}{c|}{ Paraments }} & \multicolumn{3}{c|}{ Age (years) } \\
\cline { 2 - 4 } & \multicolumn{1}{c|}{7} & 12 & 18 \\
\hline Fat mass, kg & $2.5 \pm 0.2$ & $7.0 \pm 0.3$ & $16.1 \pm 0.8$ \\
\hline P & - & $<0.001$ & $<0.001$ \\
\hline Lean weight, kg & $12.4 \pm 0.7$ & $25.9 \pm 1.1$ & $43.1 \pm 3.3$ \\
\hline P & - & $<0.001$ & $<0.001$ \\
\hline Muscle mass, kg & $9.2 \pm 10.2$ & $17.4 \pm 0.9$ & $29.2 \pm 1.9$ \\
\hline P & - & $<0.001$ & $<0.001$ \\
\hline Bone mineral content, kg & $1.2 \pm 1.3$ & $2.0 \pm 0.2$ & $2.4 \pm 0.2$ \\
\hline P & - & $<0.001$ & $>0.1$ \\
\hline
\end{tabular}

When comparing the degree of increase in various body components in 18-year-olds compared with 7-year-olds, it can be seen that the fat mass in 17-year-olds increases 6.4 times, lean mass - 3.5 times, and muscle mass - 3.2 times. The content of minerals in bone tissue in 17-year-olds had 3.0 times more as compared with 7-year-olds. Age-dependent increase in body components is especially pronounced for fat mass, compared with other components of the body

\section{Discussion}

It is known body mass index deviating from the norm is a clear sign of various pathologies and deterioration of mental and physical performance. Therefore, the analysis of body mass index in children and adolescents, when development rates are high, necessary for the prevention and correction of mental and physical activity disorders. Obtained data show in 7-year-old children were underweight but, as children grew and developed, their body mass index increased. In 17-year-old adolescents the body mass index reaches typical for this age values.

It is revealed that with the growth and development of school boys, their body component ratio shifted. In particular, fat content was $17.6 \%$ in 7 -year-olds, $21,3 \%$ in 12 -year-olds and $27.7 \%$ in 17 -year-olds. The tendency of age-related increase in the percentage of fat in boys is somewhat alarming, because this is due to the growing risk of obesity. Such phenomenon also took place in pediatric population of other regions $[7,8]$.

McCarthy et al. suggested that the ratio of fat mass to muscle mass could serve as an indicator of metabolic syndrome, given that fat excess effect on glucose sensitivity [7]. However, the relationship between fat-to-muscle mass and metabolic health may be non-linear, as complete absence of body fat, like lipodystrophy, which is associated with insulin resistance [9]. Complete absence of body fat in boys was not observed. The ratio of fat and muscle mass in 7-, 12- and 18-year-olds was equal to 0.4; 0.4 and 0.6. Thus, in late adolescence period boys will find it more difficult to maintain glucose homeostasis than earlier boys. It can be assumed that adolescents are at increased risk of predisposition to diabetes. 


\section{Conclusion}

In general, the obtained data show that as children grow and develop, the mass of main components of body increase. The most expressed increase was in adipose tissue, and the least one was in content of bone minerals. Despite the fact that 7-year-old children were underweight, the 17 -year-old adolescence had normal weight. However, weight normalization was mainly due to fat gain. It is indirectly indicated an increase in the predisposition of adolescents to the diabetes millennium.

\section{Compliance with ethical standards}

\section{Acknowledgments}

The authors would like to thank the leadership of the school number 243 of Tashkent city for the support during the study. Authors acknowledge the immense help received from the scholars whose articles are cited and included in the references of the manuscript. The authors are also grateful to the authors/editors. Publishers of all those articles and journals from where the literature for this article has been reviewed and discussed.

\section{Disclosure of conflict of interest}

There is no conflict of interest associated with this article.

\section{Statement of informed consent}

Informed consent was obtained from all individual participants included in the study.

\section{References}

[1] Jaffrin MY. Body composition determination by bioimpedance: an update. Curr Opin Clin Nutr Metab Care. 2009; 12(5): 482-6.

[2] Böhm A, Heitmann BL. The use of bioelectrical impedance analysis for body composition in epidemiological studies. EJCN. 2013; 67(1): S79-S85.

[3] Casu L, Casu L, Gillespie S, Gillespie S, Nisbett N, Nisbett N. Integrating nutrition and physical activity promotion: A scoping review. PloS one. 2020; 15(6): e0233908

[4] Franco-Villoria M, Wright CM, John HM, Sheriff A, Pearce MS, G Millennium. Assessment of adult body composition using bioelectrical impedance: comparison of researcher calculated to machine outputted values BMJ. 2016; 6: e008922.

[5] Weber DR, Leonard MB, Zemel BS. Body composition analysis in the pediatric population. Pediatr Endocrinol Rev. 2012; 10(1): 130-139.

[6] Fanzo J. Healthy and Sustainable Diets and Food Systems: the Key to Achieving Sustainable Development Goal 2? Food ethics. 2019; 4: 159-174.

[7] McClanahan BS, Stockton MB, Lanctot JQ, Relyea G, Klesges RC, Slawson DL, Schilling LP. Measurement of body composition in 8-10-year-old African-American girls: a comparison of dual-energy X-ray absorptiometry and foot-to-foot bioimpedance methods. Int J Pediatr Obes. 2009; 4(4): 389-96.

[8] Nuttall FQ. Body Mass Index: Obesity, BMI, and Health: A Critical Review. Nutr Today. 2015; 50(3): 117-128.

[9] Frayn KN. Adipose tissue and the insulin resistance syndrome. Proc Nutr Soc. 2001; 60: 375-380. 